\title{
ON SOME CENTRAL AFFECTIONS OF VISION.
}

\author{
BY W. J. DODḌs, M.D., D.SC., \\ Montrose Royal Asylum.
}

The labours of Ferrier, Munk, Goltz, and others have done much during the last few years to advance our knowledge of the sensory functions of the brain, especially of the cerebrum. They have used the experimental method, and their conclusions apply primarily not to man, but to the monkey, dog, and other lower animals.

The spectacle of doctors disagreeing is one that many people can observe with equanimity, and some few, unfortunately, with unaffected pleasure, especially when the doctors are vivisectionists; and the moral can be so easily pointed. In this question of the functions of the cerebrum, the results are no doubt differently interpreted by Ferrier and Goltz. It would be strange if there were not differences in so complicated a problem as that of the functious of the most highly organised of matter. But putting aside the rival interpretations, there still remains to us the solid store of facts which these observers have accumulated, and the influence of which is already perceptible in the fresh impetus given to the clinical and pathological investigation of the functions of the human brain. It is to this clinico-pathological aspect of the question that we propose to direct attention in this paper.

A few years ago Ferrier, searching the records of cerebral disease for mention of affections of sight, hearing, and the other senses, met with such poor success, that he concluded the latency was not a latency of symptoms but of observation. The justness of this criticism is indisputable, and the recent progress of this department of medicine has amply vindicated it. To take the affections of sight as an example; the last ror. vilx. 
decade has seen marked advance in our knowledge of amblyopia, hemianopsia, "psychical blindness," and word-blindness ; and we find that in certain cerebral diseases affections of sight instead of being rare occurrences, are as frequent as the occurrence of aphasia.

There are many ways in which the problem of the functions of the brain and their localisation may be approached by the physician. We shall limit ourselves here to the consideration of sight and its connections; and we shall find it convenient to divide the subject into two parts; the first treating of sight and its associations, or, to adopt a more physiological phrase, visual reflexes, using the word reflex in a very broad and perhaps strained sense; the second, treating of the localisation of these reflexes in the brain.

\section{Visual Reflexes.}

Much confusion has arisen from the introduction of the terms of a subjective psychology into the study of -objective brain physiology. Writers have puzzled their readers, and often we fear themselves, in their attempts to define consciousness, and distinguish between sensation, perception, apperception, cognition, and the like. These abstract distinctions have their-value and their place, but we must not forget that they are merely stations that a subjective psychology has made, not found, on the unbroken line of a continuous nervous process. It will be our endeavour to banish these terms as far as possible from our inquiry, and to proceed as objectively as we can.

Stated briefly, our aim is to note the effect produced on a person by the sight of different objects. It may be that light, and light alone, has influence on him, and that the contraction of the pupil is the only reflex that can be roused; or he may notice persons and things, and follow them blankly with his eyes; or he may grasp at objects which are offered him, and yet not know what they are, or how to use them. A still higher development may be reached, and the sight of food may suggest the movements requisite for eating; well-known faces may be recognised, writing understood, or the most complex visual pictures and symbols appreciated and acted on. 
It is of course absurd to think of enumerating all the visual reflexes that are to be found even in a man of the meanest intellectual endowments. The most laborious lexicographer would shrink from the task of compiling a table of contents of even this one department of the human mind, though there is certainly a limit to its contents. We can, however, divide the visual reflexes into certain great classes, and arrange them in an order advancing from the simple to the complex, from the completely organised to the least organised, from the stable to the unstable, preserving, in fact, as far as possible, the order of their evolution, the inverse of which is the well-known order of dissolution or regression upon which Herbert Spencer and Ribot lay such stress in their writings.

Such a classification will demand a wide and careful investigation. For this purpose the dawn of the visual reflexes must be observed in iufunts, and such observations as Darwin's and Preyer's pressed into service. In the same way the gradual lapsing of the reflexes in the decay of age will be of use. The phenomena of sleep, somnambulism, mesmerism, automatism, will all yield valuable information, which can be supplemented by an examination of the state of the reflexes in the different stages of the action of anæsthetics, and of toxic agents such as alcohol. Then, too, the field of observation must include the visual reflexes in idiocy and imbecility; in the peculiar mental states that follow epileptic and paralytic attacks; in word-blindness and the allied affections; and in that most complicated group of all, insanity.

One of the chief difficulties in satisfactorily grouping together the visual reflexes, and arranging the classes in an order advancing from the simple to the complex, lies in the fact that the simplest and most direct reflexes are, by the clustering of associations around them, gradually raised into the position of complicated and involved reflexes. The retino-muscular reflexes, for instance, that are concerned in focal and axial adjustments, and that are associated with the idea of distance, are among the simplest of the reflexes, and are developed in our earliest childhood. For example, a child soon learns only to grasp at what is approximately within reach. But these same reflexes in the mariner, the sportsman, the land- 
surveyor, are by a process of education associated with much juster ideas of distance; and their suggestions are checked by a variety of other recollections. Thus, although these retinomuscular reflexes are the basis of all ideas of distance, yet it would not be a natural classification if we regarded all. judgments of distance as contained within this elementary group. To take another example: there are certain protective visual reflexes that form a very convenient clinical group. In this group we include such acts as blinking, when a finger is thrust up to the eye; starting, if a sudden stabbing movement is made with a knife; aversion, if a red-hot poker is offered, or if a cup of steaming water is held to be drunk out of. These reflexes are based on some of our earliest and most powerful impressions, and they constitute a group of what may. be called low and well-organised reflexes. But it is difficult to formulate an accurate definition of the group, for it gradually shades off into higher reflexes, based on less frequent or less powerful impressions, and exhibiting greater intellectual action. This is a difficulty that is felt in all the groups, but it must not discourage; it is felt in all classifications, for nature abbors sharp distinctions and dividing lines as much as she does a vacuum. Another difficulty is the order in which these groups of reflexes should be arranged. The evolution of individuals differs within great limits, and reflexes that are firmly organised in one are incompletely organised in another. The groups that we offer are merely provisional, and are put forward as an indication of the line on which we ought to proceed in building up the reflexes, and more especially as a guide in the examination of cases; for it is by such a regular and orderly examination of the reflexes in connection with sight, hearing, and all the senses, and by endeavouring to distinguish the different associations that are concerned in them, that we may hope to arrive at a satisfuctory knowledge of the mental condition of a patient.

'Ihere is need of a word of caution here against the error of concluding that a reflex is lost because it is not immediately forthcoming. It may be held in check and prevented by some inhibitory power. What we call the will may from sheer contrariety set itself to counter-work the ordinary reflex 
actions, or it may be urged to this course by powerful motives. Again, the attention may be so concentrated on some particular thought, that the visual impressions die away, and lack strength to call forth the usual reflex; the fixed ideas of certain forms of insanity furnish us with the best illustration of this variety, which also includes cases of abstraction, reverie, dominant ideas, \&c. Or it may be that the reflexes; especially the higher ones, are not obtained; because of the want of attention. It is important to remember and avoid these sources of fallacy, in deciding on the condition of the reflexes.

We can imagine objectors saying, "Well, suppose you get the so called visual reflexes properly grouped together, and something like a natural classification formed, of what use will it be? You are not dealing with sight alone; in your visual reflexes there is a regular jumble of sight, touch, hearing, the kinæsthetic sense, in fact of all the senses, with a few of the appetites, several distinct instincts, and the whole group of the higher faculties of reason, memory, judgment, attention, \&c. - such a jumble, in fact, that it is quite impossible to say where sight begins or where it ends, or in some of the reflexes to see what sight has to do with them at all."

With most of this criticism we should cordially agree. We are not dealing with sight alone, with sight defined as sensitiveness to light, or mere ability to see form and colour. Sight has in these brain questions no such restricted meaning. It is recognised that there is sight and sight, and we speak of intellectual or psychical blindness, word-blindness, and other forms of blindness. We have, in a word, to deal with sight and its associations; with the visual pictures that are called up by the sight of an object as well as with the tactile, auditory, motor (or, as Bastian would say, kinæsthetic), and other memories that are aroused. Such an examination is, unfortunately, fraught with complexity, but complexity is inherent in the problem. The various senses are knit together in the brain in a network of associations, the plan of which. we can never hope fully to know ; but we shall do better if we work at the fringe of this network, and seek to obtain a knowledge of it rather than wenve for ourselves a new fabric, and delude ourselves with the idea that it is nature's product. The method 
of the visual reflexes has been selected, not because it furthers any $\grave{a}$ priori notions of well-defined cerebral localisation, but because it provides us with a satisfactory view of one department of a patient's mind. The splitting up of these reflexes into their component parts, and the determining in cases where they are absent, whether the affection is on the motor side, or the sensory, and in the latter case the deciding as to how far the appearances are due to disorder of the purely visual associations, or of the associations with other senses-these are problems of varying difficulty in different cases. Sometimes they are comparatively easy of solution; at other times it is impossible to urrive at a satisfactory conclusion, owing to the condition of the patient, or to our present lack of knowledge. Take, for example, the reflex of reading at sight. Does the sight of a word call up the sense at once (by recalling we will say, the picture of the object), or only after arousing the corresponding auditory sound ; or, yet again, only after arousing a suppressed articulation of the word? Until these points are settled, we cannot hope to analyse satisfactorily cases of wordblindness:

Before passing to a consideration of the various groups of reflexes, we would again emphasise the importance in casetaking of being dissatisfied with such general terms as hebetude, stupor, dementia, enfeebled intellect, impaired faculties, \&c. We should describe the facts that come before us, as far as possible grouping thein around the senses they primarily concern. We would also note the practical importance of investigating the condition of the eyes separately as well as in combination.

We shall in our view of the visual reflexes confine ourselves to what may be called presentative sight as distinguished from re-presentative sight; in other words, we shall occupy ourselves with the visual associations that the sight of an object calls forth, and not with those that are culled forth by auditory or tactile impressions, or by the internal rehearsing of a name. We shall further limit our attention chiefly to those conditions implying paralysis or loss of function, and shown by absence of the visual reflex-leaving untonched the consideration of those more complicated conditions characterised by perversion 
or exaggeration of function, excluding, therefore, hallucinations, and illusions of sight. The examples we shall give, particularly those in sections 2 to 8 , are taken mainly from observations made by Fürstner, ${ }^{1}$ Reinhard, ${ }^{2}$ Stenger, ${ }^{3}$ Zacher, ${ }^{4}$ and ourselves. We do not deem it necessary to give more than these general references.

We premise that in the cases examined there is no purely optical defect, no defect of media, of the retina, or of the optic disk.

(1.) The Light Reflexes.-Under this head we may conveniently include three phenomena:-the contraction of the pupil when a bright light falls on the retina; the dilatation of the pupil when the eye is removed from a bright to a dull light; and the emotional effects of light. The stimulus may be pleasurable and cause a smile, as is often seen in infants; or it may be too powerful, and be followed by an expression of pain, movements of general uneasiness, closure of the eyelids, aversion of the head, and raising of the hands, to the eyes.

These three phenomena should be investigated separately. The contraction of the pupil to light is the lowest and best organised of the visual reflexes; its relations to the other reflexes of this group and to the higher reflexes are not so clearly made out as is desirable. The pupil may contract to light, and yet there be no emotional manifestation of pain or pleasure, even though a strong light is shone into the eye; and conversely, the latter may be present and the former absent. Another point to be considered is the possibility of a retinal impression stimulating higher centres that inhibit this lower reflex. In studying these reflexes we must remember to exclude the contraction of the pupil that occurs on convergence of the eyes; the pupil may contract well on convergence, but badly to light.

(2.) Objeets fixed and followed by the Eye.-I'Ihe characteristic of this group of reflexes is that the eye does not gaze vacantly

'Fürstner, 'Archiv f. Psych.' viii. p. 162, and ix. p. 90.

2 Reinhard, 'Archiv f. Psych.' ix. p. 161.

' Stenger, 'Archiv f. Psych.' xiii. p. 218.

' Zacher, 'Archiv.. f. Psyclı.' xiv. p. 489 
into space if an object is held' before it or crosses its field of vision, but the object is looked at and its movements followed ; it is seen.

The fixing of an object by the eyes is by no means the simple act that it appears. Leconte points this out with great clearness in his work on Sight, and he shows that in every act of looking at an object, there are involved, besides the innate idea of direction, and the principle, almost as innate, of corresponding points, three adjustments,-the focal adjustment, whereby each eye obtains a perfect image of the object; the axial adjustment, whereby the axes of both eyes meet in the object; and thirdly, the pupil-adjustment, seen in its contraction on convergence of the eyes. Now each of these adjustments is based upon a visual reflex, so that we have the retino-ciliary reflex, the retino-ocular reflex (as we may term the arc that connects the retina with the ocular muscles), and the special retino-iridal reflex. Further, these adjustments or reflexes are grouped together and co-ordinated in the act of looking at an object, and with them are associated certain movements of the head and neck. Each of these several reflexes may be disturbed, and also the group of co-ordinated reflexes; but these are affections that belong. to the domain of the ophthalmic surgeon, and we shall do no more than mention them. Looking at things and following them with the eyes gives rise to ideas of form, size, and distance; indeed we may say that these ideas are present potentially or actually in every visual picture. Are there cases in which these fundamental ideas are seriously affected? It is only in a few exceptional cases that we are able to arrive at a conclusion. Infants who have not commenced to cheok their visual by their tactile experiences have the vaguest ideas of distance, and Cheselden's celebrated patient saw things flat as in a picture, and said that all objects seemed to touch his eyes. We are not aware of any observations on the adult which indicate an affection of these fundamental ideas.

Let us now consider the cases in which this power of seeing objects is impaired or lost. We need scarcely say that the retina is a surface, not a point, and that consequently sight may be lost in one part of the retina, and retained in unother. 
This leads us to affections of the field of vision, and of these hemianopsia is the most important.

We can only draw attention to a few of the main points in connection with hemianopsia. We should in every case determine, by the perimeter if possible, whether vision is still retained for some distance all round the fixation point, or whether the line of demarcation between the two divisions of the field of vision passes through this point. We should further determine the degree of blindness in the affected portion of the retina, ascertaining whether there is absolute amaurosis, or whether a feeble luminous sensation can still be aroused by a strong light; or, if the patient is unable to give this information, whether a reflex can be evoked by the approach of a lighted taper or by other means. We should also inquire whether the affected field of vision appears to the patient like a dark or grey surface, or whether it is an absolute blank of which he is as unconscious as of the existence of the blind spot. Investigation of these points is likely to throw light on the localisation of the lesion that produces hemianopsia. For example, we sometimes have hemianopsia accompanying the apoplectic or convulsive seizures of general paralysis, and as the lesion in these cases is regarded as cerebral, we should expect an amblyopic rather than an amaurotic condition of the affected field of vision And yet in several of these cases that have come under our notice there was absolute blindness in the affected part of the retina; no objects were seen, a lighted match thrust up the eye had no effect. Wilbrand cites some interesting cases of recovery from hemianopsia with gradual appearance of the visual reflexes, but for fuller information on this subject we must refer the reader to his work. ${ }^{1}$ Before dismissing this subject of the visual field, we may add that partial hemianopsia or sector-shaped defects of the field should be looked for, and also central and peripheral defects.

Another visual affection in which the power of fixing and following objects is lost, is amblyopia. Amblyopia, or dulness of vision, is a somewhat vague and unsatisfactory term. Its essential feature is diminution of the acuity of vision, with absenice of such ocular defect as would account for it. In

\footnotetext{
1 Wilbrand, 'Hemianopsie.' Berlin, 1881.
} 
umblyopia, objects may have to be brought up to the eye to be seen, small objects may not be seen at all, colours may be misty and indistinguishable, and objects appear pale and colourless. It is evident that-in such a state a patient will be very apt to make mistakes; he may easily mistake a sovereign for a shilling, and may fail to recognise many objects that are placed before him. It is then of fundamental importance in the method of examination we are pursuing that this question of the existence of amblyopia should be settled in every case, for the absence of the higher reflexes that we shall soon consider may depend on the simple fact that the objects are not distinctly seen, and not be due to any intellectual defect or defect of associations. A word of caution is necessary as to cases of unilateral amblyopia. Wilbrand is sceptical of the existence of such cases. in cerebral affections, although they have been described, and he dwells on the importance in cases of this sort $(a)$ of a careful perimetric examination, as hemianopsia is so easily overlooked, and $(b)$ of an enquiry into the previous visual acuity of the patient, as amblyopia may have been present before, enjoining us to remember the combinations of hemianopsias, \&c., that may be produced by bilateral brain affections. Amblyopia is one of the results of such combinations.

A third visual affection in which objects cannot be fixed and followed is amaurosis. Temporary amaurosis is a condition that deserves further enquiry. Snell ${ }^{1}$ records a case of amaurosis fugax lasting two days; and Panas a case of complete bilateral blindness lasting six hours. In the cerebral hemianæsthesia of Türck there is sometimes a temporary amaurosis; and in cases deseribed by Fürstner there was unilateral amaurusis.

(3.) Objects seen and handled.-In this group are included the reflexes that connect vision with the simpler movements of the hand. An object is held before the eyes, and it is grasped at; if placed on a table, it is seen and picked up; if the hand is offered, it is seized. For the simplest reflex of this kind there is required, (a) sight of the object, as in the previous section,

1 See ‘Ophthalmic Review,' vol. i. p. 399.

2 'Gazette des Hipitaux, 1881. 
(b) an idea of its position and distance, and (c) an idea of moving the muscles of the arm so as to reach the object. There may be no idea of what the object is; anything would be handled.

Loss of this reflex would be shown by the fact, that though objects are seen and followed with the eyes, they are not grasped by the hands. Before we can conclude such loss, however, we must remember the cautions already given, as to the state of the attention, presence of stupor, etc. As instances of disorder of this reflex, we may mention those cases in which grown-up idiots grasp at objects beyond their reach ; a patient may grasp first at one side of an object then at the other, before succeeding in the attempt to seize it. Carpenter cites an interesting case of a child three years old operated on for congenital cataract; who clearly recognised direction, but had little idea of distance; when told to luy hold of a watch, he groped at it like an infant lying in its cradle. These disorders are distinct from the clumsy grasping movements that depend on impairment of the kinæsthetic sense.

(4.) Objects associated with pain recognised and avoided.-This group implies an advance on the foregoing, in that certain sights are associated with painful experiences, and the movements are regulated by the memory of these experiences. Thus, in grasping objects, it is discovered that fire burns, an object thrust up to the eye is found sometimes to hit it; a sharp object is felt to cut. And in future an object suddenly approaching the eye causes closure of the lids, aversion of the head, protective movements of the hands; a lighted match is no longer seized; the sharp edge of a knife is shunned.

If the sight of these objects does not recall the associated idea of pain, we find an absence of these movements of avoidance. It is easy to quote instances of this. A red-hot poker may be brought up to the eye, and the patient gazes at it quite easy-minded and unapprehensive; he may even attempt to take hold of it. If he sees a lighted match blown out, he may attempt to put the glowing end into his mouth. Pretended blows cause no blinking.

(5.) Food recognised and eaten.-In this group we have a still i 'Mental Plyysiology,' p. 181. 
further advance. Among objects that are seen, some are recognised as good for eating, and they are seized and eaten-by the hands in the more primitive condition, with the aid of knife and fork, etc., in the more civilised. The sight of the object recalls the old associations formed by enting it, the associations of its taste, touch, etc. If these associations are lost, various curious phénomena present themselves. A person may not recognise food by sight, and never take it so long as it is simply held before him, being in fact in a condition no better than Flourens' pigeons, which would have died of hunger with food before them; but he will recognise it immediately it touches his lips, and devour it with delight. Or he may forget, and conceive some things to be food that are not; he may bite a watch, a flower, a key; he may be unable to distinguish soap from bread till he has tasted it; be may eat paper and drink ink; some bite everything held before them.

Some idiots and dements are not able to feed themselves, though they follow the spoon with interested eyes. Other patients are only able to feed themselves with their fingers, the sight of a knife and fork not suggesting the way to use them, or they may bungle in the use of them; they may eat soup with a fork, or try to cut with the back of their knife, or drink from their bread, and raise the saucer to their lips and bite it:

We have been considering only the commonest kinds of food and instruments of eating, such as are in daily use. If the associations are less organised, if, for example, a glass of acid were swallowed for a glass of water, or a poison-berry were taken in mistake for a hip, the act falls into a higher category.

(6.) The Visual Reflexes in walking and the allied movements.In a healthy adult sight contributes little to those guiding sensations which play such an all-important part in maintaining the balance of the body; the sensations of sight are only seriously called on when the kinæsthetic sense is impaired. Sight, however, is in constant requisition in locomotion. It enables us to walk in a straight line, avoid obstacles, go up steps readily, sit down safely, etc. When the visual associations that enter into these movements are absent or impaired. 
we find the patient stumbling against obstacles, jostling against people, running against lamp-posts, doors; or walls. In one of Reinhard's cases the patient ran against a door and stumbled against the furniture in her room, sometimes even though it was staring her in the face. She seemed incapable of judging distance, and did not know when she came up to an object, often the first intimation of the fact was her knocking against it. When she did notice an obstacle she gave it an absurdly wide offing.

Obstacles are seen, but they no longer suggest the movements that are required to avoid them. Past experience, in other words old associations, are not available, or, at all events, are not made use of. The more unusual the obstacle, the less likely is the patient to avoid it. Though able to walk about with a degree of safety at home, he may be quite unable to steer his way in an unknown house, or on uneven ground. Sight of a train noiselessly approaching, or of an open grating in a street, may suggest no danger, and cause no alteration in his course. The impairment of this reflex is also seen in a person's attempting to get on a chair, or jump down from one. There seems a want of association between the judgment of the distance involved and the movements to attain this distance.

(7.) Objects recognised and used properly.-In this group the test of recognition is the ability to use properly. In applying the test it is important to eliminate the complications that arise from the association. of sight with the other senses, especially with touch. For example, a key is held before a patient; if he points to a door and makes a turning movement with his hand, it is clear that the mere sight of it has suggested its use: But if the key has to be put into his hand, and he has to examine it with his fingers before he knows what it is, then we have to deal not with sight alone, but with sight associated with touch. A good example of this is seen in a case of Critchett's, cited by Carpenter $:^{1}$ A young woman, blind from birth, whose sight had been imparted by an operation, was not able to ascertain what an object was by sight alone; she would describe the shape, colour, glistening appearance of

Ioc. cit. 
a pair of scissors, but could not tell what they were till she had put her fingers in them. Here the sensations of touch contributed more than those of sight in determining the use of an object.

The sight of an object calls up ideas of weight, touch, smell, taste, sound, and it is by these associations that an object is recognised, and its proper use rendered possible. When these associations are destroyed, the power of recognition and use is lost, and we have one of the conditions to which Zussmaul applies the term "apraxia." Instances of this condition have already been referred to under former heads; we shall now give others that occur in connection with objects a degree less simple.

Objests of everyday use, such as a watch, penknife, book, pipe, thimble, umbrella, etc., are looked at vacantly, and no signs are made that 'betoken recognition. Even if placed in the patient's hand they are handled strangely, or played with in an idiotic manner ; the watch is not put up to the ear, or the knife opened, or the pipe put into the mouth. A match-box with matches in it is turned round and round with an air of helpless ignorance: In one case a patient knew what his bed, a piece of bread, and a fire were, but not what a needle, a shoe, or his clothes were. He may have forgotten the simplest properties of things, and may busy himself trying to bend a piece of wood or iron; indeed, a person in this condition would no doubt, if opportunity offered, good-naturedly stroke a tiger, or attempt to coax a lion. An object may be recognised as a member of a class, but not as an individual. In the higher instunces of individual recognition, call is made on finer and more numerous associations, and the act is removed from the group of comparatively simple reflexes at prèsent under consideration. Our knowledge of an object is very much a matter of the associations it arouses.

The recognition of well-known faces, though scarcely falling within the literal heading of this group, may be conveniently treated of here. The patient may have no idea that the people who wait on him are his wife and children ; an old friend is not greeted in the accustomed way; a stranger is taken for an old acquaintance. Ribot mentions a case where the physician 
was not recognised, though he came every day for fourteen months; and a patient recently told me that his wife and child, who had been visiting him, were good imitations, and well made up, but he was certain they were nothing more-for one thing, the child was not large enough.

It may be that objects are still recognised, but only dimly and with uncertainty; they appear new and strange. For example, a patient's hands may look odd and queer to him, quite different from what they used to look; and familiar places and buildings may seem so strange, that he will doubt whether he has seen thém before.

(8.) The Visual Reflexes in Dressing, etc.-Dressing is one of our acquired semi-automatic acts, and it requires that particular articles should be recognised, and their use and the order in which they should be put on known. Sometimes we find that the articles of dress are not recognised by sight; a shoe, a hat, a shawl, may be staring a person in the face, and yet suggest no ideas as to their use. He may have forgotten how to put his clothes on; he may spend an hour fumbling at his trousers, and at the end be no nearer the goal than when he started; he may put his waistcoat over his coat, or look aggrieved when a fourth coat in which he is just preparing to robe himself is taken from him. With his eyes wide open he may persist in trying to thrust things into a supposed pocket, though a moment's glanee should convince him that there is no pocket there. He may, like a celebrated Scotch professor, go about with his wife's white stocking on one leg, and his own black one on the other, and be continually doing similar acts. He may lie down on a chest of drawers, and think it is a sofa.

(9.) The Visual Reflexes in Handicrafts and Arts.-The reflexes embraced in this section are on a distinctly higher level than those previously considered, and it is correspondingly difficult to distinguish the part that sight bears in them. Still, sight and its associations enter largely into such actions as sewing, drawing, reading music at sight, boxing, digging, and the rudimentary operations of most manual employments; and it is of importance to test a patient in respect to actions of this kind to which he has been accustomed. If he is unable to 
perform them, bungling simple work, and failing in what used to cost him scarcely an effort, we have reason to conclude, due regard being paid to other disturbing influences, that the visual reflexes are impaired, and we have a valuable indication as to the state of the patient's brain. As an example of disturbance under this head, we may mention the case of a man who used to sketch well, but who after a cerebral attack would draw a man's head that a child might be ashamed of. Other examples will readlly suggest themselves to the reader.

(10.) Gestures understood.-Pantomime is the simplest form of language, and is almost universal in its application; it falls therefore to be considered before the higher reflexes that are concerned in naming objects and in reading. We should ascertain whether the patient acts properly whon a hand is held out to him. Does he protrude his tongue when we point to his mouth, or go so far as show him our own? Does he come to us if we beckon him, or does he look in the direction we point? Will he produce his knife when we go through the pantomime of sharpening a pencil; and point to his pocket? It is unnecessary for us to say more on this head, the absence or impairment of the power of understanding simple gestures betrays affection of certain visual reflexes.

(11.) Objects named. -From our earliest childhood we are accustomed to associate the sight of many familiar persons and things with their names. When this association fails, and the sight of the object does not recall its name, it is only another way of expressing the same fact to say that a visual reflex is in fault. In such a case, we have to inquire what class of objects cannot be named; whether those that we only rarely see and name, or those that we see and name almost every day of our lives; thus a man may have forgotten the names, bread, water, grass, or may not remember his wife's name. In other cases the power of naming objects may not be wholly lost; the patient may give some name closely allied, or may be able to find the name of the genus though not of the species, or may enter into a description of the article and seem to know everything about it but its name. Again, sight alone may fail to suggest the name, but sight, aided by some other sense as touch, hearing, etc., may recall it. The subdivisions of this 
group and the different points to observe are too well known to need further notice here.

(12.) Objects counted and figures read.-It should be seen whether the patient can tell or indicate the number of fingers shown him, or can count correctly a series of objects laid out before him. We may find that the patient is able to count a number of large objects, but is unable to count small objects that are placed close together; for example, a string of beads. The presence of amblyopia would explain this; but there seem to be cases where the individual objects are distinctly enough seen and yet a series cannot be followed, owing either to some fault of nervous conduction, or to some central defect, probably a kind of irradiation.

We should also determine whether the patient is able to read figures. Can he tell individual figures, and combinations of them? 2758, for example, may be read 2700, 50, 80 ; and there are many varieties into which we need not enter. Can he tell the time on a watch? Can be do simple addition? Mlle. Skwortzoff ${ }^{1}$ cites a case in which the power of reading figures was retained, while that of reading letters was lost.

It should also be noticed whether the value of the numbers is appreciated, or whether it is merely the names that are remembered. An estimate of this can be formed by the appearance the individual makes in a game at dominoes or cards.

(13.) The Visual Reflexes in Reading. - A person may see a page of print, know that it is print, be able to tell when it is upside down, notice the paragraphs, italics, capitals, and even be able to find a given place again, and yet be quite unable to read; just as he may recognise handwriting, or know his own name without being able to decipher a letter. This is the affection known as word-blindness.

A step higher, and he is able to name individual letters, or syllables, or words. He may be able to read some words and not others. He may mispronounce letters and words, or give altogether wrong names to them. He may skip words in reading, or pass over lines, or go from the middle of one line to the next. He may read in this way, and have scarcely an idea of the meaning of what he reads.

'Mlle. Bkwortzoff, 'De la Céoilé et de la Surdité des Mots.' Parie, 1881.

VUL. VIII. 
Still a step higher, and he can not only read, but can understand what he reads. Individuals who have lost this power remind us, says Mlle. Skwortzoff, of persons who remember the rules of pronunciation of a foreign language, and are able to read it without understanding a word of it. Short simple sentences may be comprehended, while complicated ones only bewilder. If the patient is aphasic, we can test his ability to understand what he reads by writing down some simple request and observing whether he complies with it. It is not sufficient to get him to turn over the page while we are reading, or point out the passage read, for we must remember that a patient may recognise a word when it is uttered and yet be unable to read it without this help.

(14.) The Visual Reflexes in Writing.-We must distinguish between ability to copy writing, and ability to write spontaneously or from dictation. Copying is in some cases merely an instance of drawing; indeed the patient may have so forgotten the once almost automatic art of writing, that he may begin at the last letter of a word instead of the first. We: should examine every patient and see whether he is able to copy written or printed text, and can convert the latter into written characters.

Writing spontaneously or from dictation is a complicated process which it is not easy to analyse satisfactorily. Many educated people can write with their eyes closed, and many cases have been reported of patients being unable to read what they had just written. As we are now dealing with sight only so far as it is the starting-point of a reflex, we must limit ourselves to the consideration of the influence sight exercises on the act of writing. Under the influence of sight the letters are kept at proper distances from one another, an approximation to a straight line is maintained, and glaring errors of orthography or composition are detected In some brain-diseases, the reverse of all this is observed ; for example, the letters are badly formed, or heaped one on the top of the other, or the lines may not be kept to, or a commencement is made in the absurdest places, or striking errors pass unnoticed. Examination of the writing of a patient should not be omitted where an inquiry is being made into the condition of sight. 
(15.) Higher Visual Reflexes.-We are now arrived at the more complex and less organised reflexes which it is difficult to group together satisfactorily, and we shall be content with the easier plan of pointing out the steep and thorny way of investigation instead of treading it ourselves. Are the more complex and intricate visual presentations understood by the patient as they once were? Can he remember his way about in his own neighbourhood or in less familiar districts? Does he grasp the significance of what he sees happening around him? If, for example, he saw two men fighting desperately, would he recognise the fact, or merely stare at them, or think they were amusing themselves? Does he appreciate changes of facial expression and demeanour? Is he as alive to beauty of form or colouring? Does he understand symbols and symbolic actions? In other words, are the same delicate associations called up by the sight of objects as formerly were? 'These higher visual reflexes carry us into the highest reaches of the mind, and their analysis and due appreciation naturally present difficulties that are great even where normal brain-action is under consideration. How much greater are they when the problem is overlaid by the vast disturbing influences of disordered brain-action and its offspring, protean Insanity! But are we entitled to conclude that sight is unimpaired until these higher regions of intellectual sight have been explored? For our part we think not, and we would not hesitate to say that if a Wordsworth became as a Peter Bell, no longer feeling the witchery of the soft blue sky, regarding a primrose by a river's brim as but a yellow primrose and nothing more, he would in our opinion be suffering from an undoubted visual defect.

We have confined our attention chiefly to the intellectual side of vision, but in a complete view of the subject regard. would also be had to the manifestations of the emotions that are called forth by sight.

To be continued. 